\title{
ON THE IRRITABILITY OF THE MUSCULAR FIBRE.
} Bj MARSHALL HALL, M.D., F.R.S.

A WELL-KNown physiological reviewer has often, in his various publications, kindly called my attention to the experiments and reasoning of Dr. J. Reid on "Muscular Contractility", as published in the Edinburgh Monthly Medical Journal in 1841, and recently reprinted in that distinguished author's Physiological Researches. He has, in particular, done me the same service no less than twice in the last number but one (No. vI) of the British and Foreign Medico-Chirurgical Revievo. At page 449 of that work, he observes: "Whilst we thus fully recognize the correctness of the facts adduced by Dr. M. Hall, and admit the value of this new means of Diagnosis (which, however, even on his own admission, is by no means constantly to be relied on), we must still express our dissent from his theoretical interpretation of these phenomena, namely, that the irritability of the muscles is derived from, or directly dependent upon, the spinal cord. Nothing can, to our minds, be more convincing than the proof afforded by Dr. J. Reid's experiments, that the muscular irritability is the proper endowment of the tissue itself, depending (like other vital properties) upon its state of nutrition, which, in its turn, is regulated, ceteris paribus, by the degree in which the muscle is exercised. Dr. Reid has shown that the irritability of muscles may be maintained for any length of time after the complete division of the nerves, if they be duly exercised; and he has further shown, that it may be recovered, under the same circumstances, after it has been entirely exhausted. How, then, is it possible that this property can be derived from the spinal cord? Dr. Hall has never, so far as we are aware, attempted to explain these results, but persists in his old theory, as if they had never been presented. It is not difficult to explain all the facts adduced by him, in accordance with the doctrine which we'advocate. For it is obvious, as Dr. Reid has shown, that the continuance of the connexion between the muscles and the spinal cord, after the influence of the brain has been withdrawn, will tend to sustain the nutrition, and therefore the irritability, of the muscles, in consequence of the occasional excitation of reflex contraction in them. On the other hand, as the irritability is not liable to be exhausted by cerebral influence, it will tend to increase, so that contractions will be occasioned by slighter stimuli; at the very same time that the whole pover of the muscle is undergoing diminution, in consequence of its impaired nutrition."

I have endured many a lecture from the same source; and, but for the sake of truth and that science which I cultivate, would endure them on, especially as no insincere feelings of regard towards the author of the paper in question, would also deter me from (to $m e$ ) the ungrateful task of the critic, when it leads to expressions of dissent.

The question before us is this: On what influence does this irritability of the muscular fibre depend? I have stated that this faculty is in strict dependence on the spinal centre. Dr. J. Reid maintains that it is independent of this centre, and dependent on the condition of nutrition. The appeal must be to facts. Let us then consider, or rather, reconsider the following case. 
A patient is affected with hemiplegia of the right side of two years' duration. The right arm is nearly powerless; its bulk is so reduced that its circumference is one-fourth of an inch less than that of the left, usually the smaller of the two, and its temperature is also less than that of the unaffected side. The nutrition, I repeat, is impaired. Yet the irritubility of the muscular fibre, carefully tested by galvanism, is far greater than that of the unparalysed limb! All the argumentation in the world cannot gainsay this fact, witnessed very recently by many competent judges, and which is only repeated here, having been stated in my former publications. The nutrition, then, is greatly diminished, the irritability greatly augmented! Why should it be necessary to say more? But in hemiplegia, the paralysed muscles, paralysed quoad the cerebrum, are still in connexion with the spinal centre. Let us now consider how the case would be if, instead of this, the same muscles were paralysed quoad the latter. I adduce an experiment from Dr. J. Reid himself.

" EXPER. 1I. The sciatic nerve was divided in a rabbit, and a portion of it removed. Seven weeks after the operation, the animal was killed by a dose of prussic acid, and the muscles of both posterior extremities were exposed and irritated by the direct application of the wires of a galvanic battery to the muscles. 'The muscles of the leg of the paralysed limb contracted very feebly, while those of the other leg were thrown into powerful contraction. The muscles of the leg of the paralysed limb were evidently much smaller, paler, and softer, than the corresponding muscles of the opposite leg."1

I venture to designate the former cerebral, the latter spinal paralysis. In the first, the irritability of the muscular fibre is augmented; in the second, it is diminished; in both, nutrition is impaired. What is the cause, the "fons et origo" of this difference? Can any one refuse the conclusion, that the continued influence of the spinal centre on the muscular fibre is that cause? Can any one resist this conclusion-that augmented irritability and diminished irritability are compatible alike with diminished nutrition? therefore-that irritability does not depend on, however it may be modified by-as it must undoubtedly be, cateris paribus - the state of the nutrition. I now beg to adduce another of Dr. J. Reid's experiments.

" ExPER. I. The sciatic nerve was divided in a rabbit, and a portion of it removed. One wire from two galvanic batteries of thirty pairs of plates, was applied over the course of the nerve, and the other wire was applied over the foot, which was kept moist, until the muscles had ceased to contract. Three days after this, a weaker battery was used, and the muscles of the limb had recovered their contractility, and contracted powerfully. The more powerful battery was used as before, until the muscles had ceased to respond to the excitation, and three days after this they had again recovered their contractility."

The question is-how is this fact to be explained? In answering this question, I must briefly adduce some new views, unknown probably to Dr. J. Reid at the time this paper was penned and repenned, and anknown probably to the reviewer and to Dr. Todd, who has also attempted

1 Researches, p. 10.

Op. citat. p. 9. 
to investigate this subject. When the galvanic current has once passed along the muscular fibre, that fibre is no longer in the condition in which it was previously. It is in a state or condition which I have rentured to designate the electrogenic, a condition produced by the current. This condition is such, that the repetition of that current ceases to effect any contraction in the muscle, the irritability of which is not, as Dr. J. Reid supposes, diminished, but rendered inoperative. . This is seen by reversing the direction of the current, when the muscle contracts, as before, instantly. Or the same phenomenon is seen by suspending the original current for a very short interval, and repeating it without change. All this I was about to bring before the Royal Society; but it was contrived to renew the Prochaska calumny, and to get my labours black-balled there.

But to return :-I helieve Dr. J. Reid's supposed diminished irritability or contractility in this experiment, was an electrogenic state. I will now adduce his third experiment.

" ExPER. III. The spinal nerves were cut across, as they lie in the lower part of the spinal canal, in four frogs, and both posterior extremities were thus insulated from their nervous connexions with the spinal cord. The muscles of one of the paralysed limbs were daily exercised by a weak galvanic battery, while the muscles of the other limb were allowed to remain quiescent. This was continued for two months, and at the end of that time, the muscles of the exercised limb retained their original size and firmness, and contracted vigorously, while those of the quiescent limb had shrunk to at least one-half of their former bulk, and presented a marked contrast with those of the exercised limb. The muscles of the quiescent limb still retained their contractility, even at the end of two months; but there can be little doubt that, from the imperfect nutrition of the muscles, and the progressing changes in their physical structure, this would in no long time have disappeared, had circumstances permitted me to prolong the experiment."

This experiment is obviously incomplete. It suggests, however, one important remark-a remark made by the author against myself-that " before we lay down a law in any of the sciences,-or, in other words, arrive at a true generalization,-it must include all the facts of the case." I If there be no other difference, that is, in scientific language, cateris paribus, the irritability in two limbs, equally deprived of the influence of the spinal centre, as of any other, ought to be the same, augmented or diminished; but if another influence be added, it must, of course, produce its own effect. In the experiment under discussion, a new difference-a new element-is added, which does not affect the original question.

But I have another remark to make. The case is one not of physiology, but of pathology, - a fact neglected by many physiologists. In physiology, and cateris paribus, the more stimulus is applied to muscles, the less their irritability; compare, for example, the state of activity with that of rest, throughout the animal kingdom. To this law Dr. J. Reid's experiment affords an exception. What is the precise nature of this exception? I would suggest its cautious repetition.

$$
\text { Op. ritat. p. } 12 .
$$


Besides the influence of the spinal marrow, of nutrition, and of the electrogenic state, there are other influences which affect this irritability or contractility of the muscular fibre, which require investigation. One of these is, that of the condition of the blood in the minute and intermediate vessels in the muscular structure, subjected to the experiment. It is obviously different in the galvanized and ungalvanized limb, being more moved, perhaps more aërated, in the former.

In these experiments, many circumstances must be taken into account which have hitherto been overlooked. Some of these are-1, the direction of the current; 2, the continuity, or repetition, of the current ; 3, the change of the current; 4, the electrogenic effect of the current; 5, the force of the current; for this may be-1, physiological ; 2 , pathological: it is the former, I believe, in my experiments read to the Royal Society ; it is the latter, in many of those of Signor Matteucci.

The question, in all its bearings, is not a simple or easy one, or one to be fathomed by an experimenter who can, in physiology, confound the results of the pure current of a galvanic trough with those of the recurrent current of an electro-dynamic machine, as Dr. Todd has done.

Dr. J. Reid observes, p. 13, in reference to my experiments :

"1. As the muscles of the limb in which the sciatic nerve had been cut, could only be called into contraction by direct excitation of the muscular fibre, while the muscles of the limb in which the excito-motory movements were retained, could be called into contraction both by direct excitation of the muscular fibre, and also by excitation of the skin, it is obvious that the more vigorous contractions observed in the limb in which the nerve had been left entire, may have been partly dependent upon the galvanism acting as an excitant upon the skin in the one limb, and not in the other. That galvanism can act as an excitant upon the skin, and produce vigorous excito-motory movements, we have satisfied ourselves by experiment."

The reply to this is, in words quoted from me by Dr. J. Reid, at p. 12, that " the difference in the degree of irritability in the muscular fibre of the two limbs, was observable when they were entirely separated from the animal."

Dr. J. Reid adds :

"Though the muscles of the posterior extremity of a frog no longer respond to the motive influence of volition, after the spinal cord has been cut across, yet if the excito-motory movements remain, these muscles, as we have satisfied ourselves by experiment, may be occasionally thrown into contraction by various causes, such as the rubbing of the skin against the surface of the vessel in which the animal is placed, when it crawls onwards by the action of its anterior extremities, while those of the limb in which the nerve has been cut remain perfectly quiescent. And if this be the case, it is obvious that these occasional muscular contractions, in the one limb, may retard, or perhaps arrest, in the muscular bundles of that limb, those physical changes which are incompatible with the manifestation of the property of muscular contractility."

It has already been proved by the fact of augmented irritability in the emaciated hemiplegic limb, that such "physical changes" are not " in- 
compatible with the manifestation of the property of muscular irritability", as Dr. J. Reid supposes.

I will now conclude this brief note. I may be allowed some credit for forbearance when I mention, that it is eight years since the first publication of Dr. J. Reid's paper, during which time I have been goaded to a reply, and yet I have abstained, obviously not because that reply was not the easiest thing in the world. I would not write this reply, even now, if to do so did not afford me the opportunity of saying that, however I may sometimes differ from him,-and my difference is not that of a biblio-physiologist and of a pædo-critic, but of a labourer and of a veteran,-I regard Dr. John Reid as amongst the very first of the physiologists of our time and country.

P.S. I do not know that any thing I have ever published, has pledged me either for or against the Hallerian doctrine, as Dr. J. Reid seems to suppose. In nature, every motor action seems to be excited by the nerves as a medium. But galvanism may excite the muscles by penetrating, as the nerves do, their very substance. Nay, I think there is reason for believing that, whilst an electric current of great intensity acts on the nerves, and through these on the muscles, a current of low intensity acts on the muscular fibre directly. But much cautious experiment is still required to determine this question. In general, the nerve is the excitor, the muscle the excited, in all muscular movements. The vis nervosa and the vis muscularis are distinct, though they may act in unison, and probably each may be injured or destroyed without the other.

The vis nervosa may be augmented in the spinal centre. May either this in nerves or the vis muscularis undergo a similar augmentation? And, what are the distinct seat and the limit of shock? Is the spinal centre alone, or are the nerves and muscles also affected? The heart is involved in its effect. If shock affect the muscular irritability, and if this irritability be gradually restored, what bearing have these facts on our original question? In determining the whole question, the difference between the irritability of the fibre, and the power of the mass, must be constantly kept in mind-a precaution hitherto omitted by the gentleman whom I have quoted.

London, July 1849. 